\title{
The Role of an Electronic Resources Librarian in Procuring Accessible Online Resources
}

\section{Authors: Hannah McKelvey}

This is an Accepted Manuscript of an article published by Taylor \& Francis in Serials Review on 2020-06-01, available online: https://www.tandfonline.com/10.1080/00987913.2020.1772012.

McKelvey, Hannah. "The Role of an Electronic Resources Librarian in Procuring Accessible Online Resources." Serials Review 46, no. 2 (April 2, 2020): 76-81. doi:10.1080/00987913.2020.1772012.

Made available through Montana State University's ScholarWorks 


\section{The Role of an Electronic Resources Librarian in Procuring Accessible Online Resources}

Hannah McKelvey, Electronic Resources \& Discovery Services Librarian, Montana State University Library 


\section{Abstract:}

Per the 2019 NASIG Core Competencies for electronic resources librarians (ERL), ERLs "work with concepts and methods that are very much in flux ... [they are] knowledgeable about the legal framework within which libraries and information agencies operate... [including] laws relating to... equal rights (e.g., the Americans with Disabilities Act)". However, the Core Competencies do not define the level to which an ERL is responsible for determining the accessibility of an electronic resource. This article aims to create a better understanding of the steps an ERL can take to develop an accessibility statement pertaining to procuring accessible content. This article synthesizes key laws and policies that ERLs should be aware of in order to draft an accessibility procurement statement for their institution. It will also discuss licensing strategies, documentation collection, and conducting potential audits of electronic purchases. 


\section{Introduction}

As many libraries procure access to online content from third-party providers, ensuring that the content is fully accessible to every user poses a challenge to those responsible for facilitating access to the resources - especially electronic resources librarians (ERL) who are often responsible for evaluating online resources and negotiating the license agreements for the content. In 2015 alone, "academic libraries at top tier institutions in North America spent 78.8 percent of their total materials budgets on electronic resources" (PCG, 2017). With libraries spending most of their materials budget on electronic content, it's important that the content is accessible. Much of the literature that exists today highlights tools that ERLs should consider using to test the accessibility of electronic content their institution is considering acquiring (Rysavy \& Michalak, 2020). It also includes the work of multiple libraries who have audited the accessibility of their existing third-party resources (Fernandez, 2018; George \& Coussement, 2016; George, Clement, Hudson, and Asif, 2014). However, little of the literature discusses what the role of an ERL is in procuring accessible content, nor how in depth their understanding of accessible computing should be to ensure that electronic, third-party content follows universal design principles (DeLancey, L. \& Ostergaard, K., 2016; Ostergaard, K., 2015).

Per the 2019 NASIG Core Competencies, ERLs "work with concepts and methods that are very much in flux ... [they are] knowledgeable about the legal framework within which libraries and information agencies operate... [including] laws relating to... equal rights (e.g., the Americans with Disabilities Act)" (NASIG, 2019). While ERLs should be familiar with the Americans with Disabilities Act (ADA), “a civil rights law that prohibits discrimination against individuals with disabilities in all areas of public life" (ADA National Network, 2020), they should also be knowledgeable about other laws that could impact their work. In addition to the 
ADA Act, an ERL should have awareness of the Rehabilitation Act of 1973 and the specific sections of the Act, Sections 504 and 508, that mandate electronic accessibility requirements for government or other programs that receive federal financial assistance.

National and State Requirements for Accessibility

While there aren't any explicit laws in the United States that require private websites to be accessible, Section 504 of the Rehabilitation Act of 1973 "prohibits discrimination against people with disabilities in programs that receive federal financial assistance" (Disability Rights Education \& Defense Fund, n.d.); and "universities that receive federal financial aid are required by law to make reasonable accommodations to ensure their web content is accessible to everyone" (McKenzie, 2018). Institutions that receive federal funding must also comply with Title II of the Americans with Disabilities Act of 1990, "prohibiting discrimination on the basis of disability by public entities" (Nondiscrimination on the Basis of Disability in State and Local Government Services, 2019). In 1998, the Rehabilitation Act of 1973 was amended to include Section 508, a law that "requires federal agencies to develop, procure, maintain and use information and communications technology (ICT) that is accessible to people with disabilities" (Environmental Protection Agency, 2013). It is "widely accepted that colleges and universities are subject to [Section 508] requirements under Title II because they almost universally receive some form of federal funding" (LaGrow, 2017).

In January 2018, Section 508 was revised to include the Web Content Accessibility Guidelines (WCAG) 2.0 level AA as the standard for "websites, electronic documents and software" to follow (General Services Administration, n.d.). The World Wide Web Consortium (W3C) developed these guidelines, which focus on four principles of web accessibility: perceivable, operable, understandable, and robust (World Wide Web Consortium, 2020; Boyd, 
2019). While these guidelines were developed by the W3C and are considered international guidelines, in many accessibility-related court cases in the United States, the courts have ruled that institutions should consider these guidelines as best practices for creating or procuring accessible online content (United States Department of Justice, 2016). In 2009, the Council of the American Library Association also adopted a resolution recommending that "all libraries purchasing, procuring, using, maintaining and contracting for electronic resources and services require vendors to guarantee that products and services comply with Section 508 regulations, Web Content Accessibility Guidelines 2.0, or other applicable accessibility standards and guidelines" (Council of the American Library Association, 2009).

In recent years, many states have also adopted what are referred to as 'Little 508's' including Alabama, Arizona, California, Connecticut, Illinois, Indiana, Kansas, Louisiana, Massachusetts, Minnesota, Missouri, New York, Oklahoma, and the Virginia Information Technologies Agency (U.S. General Services Administration, n.d.). These state policies require Electronic and Information Technology (EIT) to be fully accessible. Electronic resources librarians in these states working in public institutions should be aware of these requirements for accessible online content. States that have not adopted a 'Little 508,' may still have state statutes that inform ERLs of considerations that need to be taken when procuring online content. For example, Montana's state legislature passed a technology access clause requiring that all "technology purchased in whole or in part with funds provided by the state that is to be used for the creation, storage, retrieval, or dissemination of information and that is intended for use by employees, program participants, and the public must be accessible to and usable by individuals who are blind or visually impaired" (Montana Code Annotated, 2019). As this clause pertains to 
electronic resources purchased by a Montana library, electronic resources librarians should be aware of it.

Local Requirements

With an onslaught of lawsuits in recent years (Office of Civil Rights, n.d.), many universities are now creating centers that support the development of accessible content on their campuses and address issues that have been presented in the lawsuits. Montana State University's Academic Technology \& Outreach Department has created an 'Accessibility for All' program that "support[s] instructors making educational content accessible for students with disabilities" (Montana State University, n.d.). It may be worth it for an ERL to begin establishing relationships with centers or departments on their campus focused on accessibility or at least be aware of these types of programs as potential resources. Additionally, many universities have developed policies about general web accessibility; ERLs should educate themselves on this policy. ERLs should also contact their campus legal services about any specific license clauses used when procuring software for the university. They may also want to get approval on any accessibility clauses that they are considering inserting into library agreements with third parties to ensure it aligns with any local procurement or licensing requirements. In summary, ERLs should familiarize themselves with the following national, state, and local requirements and incorporate this knowledge into their procurement workflows.

\section{National (United States)}

- ADA Title II

- Sections 504 and 508 of the Rehabilitation Act of 1973

- World Wide Web Consortium (W3C) Web Accessibility Initiative (WAI) 


\section{State}

- Learn if their state has a Little 508

- Check if there are any specific statutes in their state pertaining to the accessibility of technology — most university legal counsels should be able to answer this

\section{Local}

- Be aware of any library or campus technology procurement policies

- Look for any campus web accessibility policies

- Work with their campus legal services, if they have one, to learn more about local accessibility requirements

While it is not feasible to expect ERLs to be adept at all forms of adaptive technology and to conduct in-depth audits of resources their institution is considering procuring, they can serve as advocates for accessibility by incorporating small changes into their procurement routines. Understanding key legal requirements will help ERLs begin incorporating these changes into their process.

\section{Incorporating Accessibility Practices into the Workflow}

As electronic resource librarians begin to understand their role in procuring accessible online content in relation to the policies and laws in existence at the national, state, and local levels, this knowledge will help determine how to fit accessibility best practices into their workflow in terms of developing local procurement policies, negotiating licenses, and evaluating content. When beginning to think about this, ERLs should consider how to approach the following three areas of procuring an electronic resource:

1. licensing language 
2. accessibility documentation

3. point-of-contacts.

Understanding the key policies in the section above will give an ERL a better grasp on what language is appropriate to include in a license agreement. The Big Ten Academic Alliance has a license clause that references key policies and includes language that would allow the licensee to adapt a resource to make it accessible, if necessary. The clause is broad enough that it could be used by any institution or modified to fit the state and local requirements of a specific institution. If the third-party has an existing accessibility clause that is inadequate, or they do not have one at all, an ERL should ask them to insert something like the following language into the agreement (or a revised version that fits their local and state requirements):

Licensor shall comply with the Americans with Disabilities Act (ADA), by supporting assistive software or devices such as large print interfaces, text-to-speech output, voiceactivated input, refreshable braille displays, and alternate keyboard or pointer interfaces in a manner consistent with the Web Accessibility Initiative Web Content Accessibility Guidelines 2.0 AA. Licensor shall ensure that product maintenance and upgrades are implemented in a manner that does not compromise product accessibility. Licensor shall provide to Licensee a current, accurate completed Voluntary Product Accessibility Template (VPAT) to demonstrate compliance with accessibility standards. If the product does not comply, the Licensor shall adapt the Licensed Materials in a timely manner and at no cost to the Licensee in order to comply with applicable law. Nothing in this Agreement shall limit the Licensee or any end user from making lawful, noninfringing uses to facilitate access to the Licensed Materials by users who have disabilities. For the avoidance of doubt, the Licensor authorizes such uses. 


\section{Licensing an Inaccessible Product}

Occasionally, there are very specialized resources that subsets of users may request a library to purchase or subscribe to in order to advance their research that might not meet accessibility standards. While an ERL would follow the same procurement procedures for any resource, they might consider proposing a clause in the license agreement that acknowledges this and would allow the library or the end user to modify the resource only for making it accessible:

Licensor acknowledges that at the time of this agreement, [name of product] does not support assistive technologies and may be in breach of the Americans with Disabilities Act and Section 508 of the Rehabilitation Act of 1973. If requested by the Licensee, the Licensor shall adapt the Licensed Materials in a timely manner and at no cost to the Licensee in order to comply with applicable law. However, if Licensee is unable to meet this request, nothing in this agreement shall limit the Licensee or any end user from making lawful, noninfringing uses to facilitate access to the Licensed Materials by users who have disabilities. For the avoidance of doubt, the Licensor authorizes such uses.

In addition, an ERL should contact the user or users who requested access to inform them that the resources may not be compatible with assistive technologies before they move forward with procuring the resource to ensure their research team will be able to use the product. Lastly, if an ERL determines that an inaccessible product will be widely used, they may consider conducting an audit or evaluation following the procedure below. Depending on the outcome of an internal evaluation and the strictness of a specific institution's policies around accessible technology, the ERL may suggest to not move forward with procurement. 
Accessibility Documentation

\section{Voluntary Product Accessibility Template}

Most third-party resource providers have completed a Voluntary Product Accessibility

Template (VPAT), which is a document that explains how online resources comply with Section 508 accessibility requirements. Electronic resources librarians can ask for this document to file alongside the fully executed license agreement. In 2016, Laura Delancey also created the VPAT Repository to help increase the visibility of this documentation to libraries.

\section{Other Accessibility Evaluations}

While the VPAT is what most libraries collect, an ERL may consider accepting an accessibility evaluation of a product from an accessibility consultant or a known accessibility expert. The ERL would then need to determine the validity of such an evaluation before it was accepted in place of a VPAT.

\section{Auditing \& Evaluating Resources Accessibility Checkers}

While most external resource providers are doing their best to meet current accessibility standards, sometimes a vendor does not have a VPAT and isn't willing to complete one. This means an ERL might consider conducting a high-level audit of a resource their institution is considering procuring to assess if the resource complies with basic WCAG 2.00 AA guidelines. While this seems like a daunting task, if an ERL only audited a homepage, they may be able to glean enough information to assess the rest of the website. Per WebAIM, "home pages are very often the most accessed pages on a web site and are the gateway to the rest of a web site's content... research indicates a correlation between issues detected on a home page and other site 
pages" (WebAIM, 2019). However, the ERL should align the scope of a resource audit with any requirements specific to the institution procuring the resource.

While there are a slew of browser extensions and plugins that exist to audit the accessibility of online content, WAVE, an automated accessibility checker created by the wellknown nonprofit WebAIM, is one the most commonly recognized. Per the LYRASIS 2019 Accessibility Survey Report, the WAVE tool was reported as the most used by respondents. It's important to understand that any automated accessibility checkers, including WAVE, are intended to highlight issues as well as the accessible features of a website, but only a human can determine if a website is truly accessible.

Additionally, a massive amount of effort to improve the accessibility of electronic resources has been completed by the Big Ten Academic Alliance Library E-Resource Accessibility Group, formed in 2015. The Big Ten conducts "accessibility evaluations for select vendor e-resources based upon recommendations from the member libraries and the platforms that the majority of the consortia own or are considering for purchase" (Big Ten Academic Alliance, n.d.). The results of these evaluations are openly available providing information to vendors for increasing the accessibility of their products and providing information about the accessibility of third-party content to the entire library community. In 2019, the Association of Southern Research Libraries (ASERL) partnered with the Big Ten Academic Alliance to create the Library Accessibility Alliance (LAA). Through this new partnership, LAA continues to fund a program that allows accessibility evaluations of third-party resources to continue (Big Ten Academic Alliance, n.d.). ERLs are encouraged to stay connected to the work of LAA as it benefits all libraries and their users. However, if LAA has not evaluated a resource that an ERL's 
institution is considering procuring, the section below will discuss basic criteria or 'Easy Checks' that an ERL can use to conduct an audit.

\section{What to Evaluate}

The World Wide Web Consortium (W3C) Web Accessibility Initiative (WAI) has created a resource called 'Easy Checks,' which are simple steps to determine if a resource is accessible and meets the most basic WCAG 2.00 AA success criteria. This check can be performed with or without an accessibility checker, like WAVE. One does not need to be an accessibility expert to determine if a website meets this basic list:

Page title

Image text alternatives ("alt text") (pictures, illustrations, charts, etc.)

Text:

Headings

Contrast ratio ("color contrast")

Resize Text

Interaction:

Keyboard access and visual focus

Forms, labels, and errors (including Search fields)

General

Moving, Flashing, or Blinking Content

Multimedia (video, audio) alternatives

Basic Structure Check 
Further descriptions of the criteria are listed on a page maintained by $\mathrm{W} 3 \mathrm{C}$. Depending on the outcome of this type of evaluation, an ERL may suggest that their institution not move forward with a procurement unless the library is able to reach an agreement with the vendor or the vendor is willing to improve the accessibility of their site.

\section{Point of contact}

Whether or not a third-party resource provider is fully compliant with WCAG 2.00 AA guidelines, an ERL should ask for a point-of-contact for any requests related to alternate formats of materials or for complaints related to the accessibility of their content. Many institutions are also working to create processes for users to request remediation to library content (Montana State University Library, n.d.; Michigan State University Libraries, n.d.). This process could potentially include requests for remediation to content from a third-party provider. If the provider has given the ERL a point-of-contact, the request could be sent to the provider. However, if an ERL was successful in getting language into the license agreement that allows the library to remediate their content, depending on the level of remediation required, an institution could modify the content locally.

\section{Conclusion}

In conclusion, while accessibility is a big topic, ERLs can take steps toward streamlining their knowledge of accessibility and how it fits into their workflows by understanding key legal requirements at the national, state, and local levels. Using this knowledge, an ERL can begin to develop a guiding statement of accessibility for how their library approaches procuring accessible electronic content. Through these efforts, ERLs serve as advocates for the 
remediation, development, and maintenance of accessible content by encouraging third-party providers to meet current accessibility standards.

\section{References}

ADA National Network. (2020). What is the Americans with Disabilities Act (ADA)? Retrieved from https://adata.org/learn-about-ada

Berg, K. (2019). Website Accessibility \& the Law: Why Your Website Must Be Compliant. Retrieved from https://www.searchenginejournal.com/website-accessibility$\underline{\text { law/285199/\#close }}$

Big Ten Academic Alliance. (n.d.). Library E-Resource Accessibility - Testing. Retrieved from https://www.btaa.org/library/accessibility/library-e-resource-accessibility--testing

Boyd, Peter. (2019). How to Test Your Website for ADA and WCAG Compliance. Retrieved from https://www.forbes.com/sites/forbesagencycouncil/2019/05/08/how-to-test-yourwebsite-for-ada-and-wcag-compliance/\#4ded0b3f67bf

Council of the American Library Association. (2009). Purchasing of Accessible Electronic Resources Resolution. July 2019, 1-2. https://alair.ala.org/bitstream/handle/11213/1061/07-15-09CD52rev.pdf? sequence $=1$ \&isAllowed $=y$

DeLancey, Laura. (n.d.). VPAT Repository. VPAT Repository. (2020). Retrieved 31 January 2020, from https://vpats.wordpress.com/ 
DeLancey, L., Ostergaard, K. (2016) Accessibility for Electronic Resources Librarians, The Serials Librarian, 71:3-4, 180-185, DOI: 10.1080/0361526X.2016.1254134

Disability Rights Education \& Defense Fund. (n.d.). Section 504 of the Rehabilitation Act of 1973. Retrieved from https://dredf.org/legal-advocacy/laws/section-504-of-therehabilitation-act-of-1973/

Environmental Protection Agency. (2013). What is Section 508? Retrieved from https://www.epa.gov/accessibility/what-section-508

Fernandez, Michael. (2018) How Accessible is Our Collection? Performing an E-Resources Accessibility Review, The Serials Librarian, 74:1-4, 81-86, DOI:

10.1080/0361526X.2018.1430424

General Services Administration. (n.d.). Accessibility News: The Section 508 Update. Retrieved from https://www.section508.gov/blog/accessibility-news-the-section-508-Update

George, S., Clement, E., Hudson, G. and Asif, M. (2014). Auditing the accessibility of electronic resources. In: Hall, I., Thornton, S. and Town, S. (eds.). Proceedings of the 10th Northumbria International Conference on Performance Measurement in Libraries and Information Services. University of York, July 22-25th, 2013. pp. 95-104.

George, S. and Coussement, K. (2016). Accessibility for all: engaging library staff in auditing electronic resources. ALISS Quarterly. 11(3): 24-30. https://alissnet.org.uk/alissquarterly/aliss-quarterly-past-issues/ 
Information Technology Industry Council. (2020). VPAT. Retrieved 31 January 2020, from https://www.itic.org/policy/accessibility/vpat

LaGrow, Martin. (2017). The Section 508 Refresh and What It Means for Higher Education. Retrieved from https://er.educause.edu/articles/2017/12/the-section-508-refresh-andwhat-it-means-for-higher-education

Michigan University Libraries. (n.d.). Remediation Requests \& Information. Retrieved 31 January 2020, from https://lib.msu.edu/general/access-remediation/.

Montana Code Annotated. (2019). 18-5-603. Nonvisual access ensured, MCA. Retrieved from https://leg.mt.gov/bills/mca/title_0180/chapter_0050/part 0060/section_0030/0180-0050$\underline{0060-0030 . h t m l}$

Montana State University. (n.d.). Accessibility for All - Academic Technology and Outreach. Retrieved 7 January 2020, from http://ato.montana.edu/accessforall/

Montana State University Library. (n.d.). Accessibility Requests. Retrieved 31 January 2020, from https://www.lib.montana.edu/accessibility/

McKenzie, Lindsay. (2018). Feds Prod Universities to Address Website Accessibility Complaints. Retrieved from https://www.insidehighered.com/news/2018/11/06/universities-still-struggle-make$\underline{\text { websites-accessible-all }}$ 
NASIG. (2019). Retrieved from

https://www.nasig.org/site page.cfm?pk_association_webpage_menu=310\&pk_associati on webpage $=7802$

Nondiscrimination on the Basis of Disability in State and Local Government Services. (2019). 28

C.F.R. pt. 35. Retrieved from https://www.govinfo.gov/content/pkg/CFR-2019-title28vol1/xml/CFR-2019-title28-vol1-part35.xml

PCG. (May 20, 2017). Share of academic library serials budgets spent on electronic serials in North America from 2007 to 2016 [Graph]. In Statista. Retrieved from https://wwwstatista-com.proxybz.lib.montana.edu:3443/statistics/715381/electronic-journal-share-ofoverall-academic-library-serials-budgets-in-na/

Office for Civil Rights. (n.d.). Office for Civil Rights Recent Resolution Search. Retrieved from https://ocrcas.ed.gov/ocr-search

Ostergaard, K. (2015). Accessibility from Scratch: One Library's Journey to Prioritize the Accessibility of Electronic Information Resources. Serials Librarian, 69(2), 155-168. https://doi-org.proxybz.lib.montana.edu:3443/10.1080/0361526X.2015.1069777

Rosen, Hannah, and Jill Grogg. LYRASIS 2019 Accessibility Survey Report. July 2019, 1-42. www.lyrasis.org/technology/Pages/Accessibility-Survey-Report.aspx

Rysavy, M. D. T., \& Michalak, R. (2020). Assessing the Accessibility of Library Tools \& Services When You Aren't an Accessibility Expert: Part 1. Journal of Library Administration, 60(1), 71 -79. https://doiorg.proxybz.lib.montana.edu:3443/10.1080/01930826.2019.1685273 
U.S. General Services Administration (n.d.). State Policy. Retrieved from https://www.section508.gov/manage/laws-and-policies/state

United States Department of Justice. (2016). The United States' Findings and Conclusions Based on its Investigation Under Title II of the Americans with Disabilities Act of the University of California at Berkeley, DJ No. 204-11-309. Retrieved from https://news.berkeley.edu/wp-content/uploads/2016/09/2016-08-30-UC-Berkeley$\underline{\text { LOF.pdf }}$

WebAIM. (2019). The WebAIM Million. Retrieved from https://webaim.org/projects/million/

Weber, J. (2017). ADA Compliance for Websites - A Beginner's Guide. Retrieved from https://www.searchenginejournal.com/ada-compliant-website/200106/\#close

World Wide Web Consortium. (n.d.). Introduction to Understanding WCAG 2.0. Retrieved from https://www.w3.org/TR/UNDERSTANDING-WCAG20/intro.html\#introductionfourprincs-head

World Wide Web Consortium. (n.d.). W3C Accessibility Standards Overview. W3C Accessibility Standards Overview. (2020). Retrieved from https://www.w3.org/WAI/standards-guidelines/

World Wide Web Consortium. (n.d.). Web Accessibility Evaluation Tools List. Retrieved from https://www.w3.org/WAI/ER/tools/ 